\title{
Análise comparativa da espermiogênese normal e diapáusica em percevejos fitófagos (Hemiptera, Pentatomidae) - Revisão
}

\begin{abstract}
Adrienne de Paiva Fernandes ${ }^{l}$
RESUMO - Percevejos fitófagos (Hemiptera, Pentatomidae) são as principais pragas de colheitas economicamente importantes ao redor do mundo, como soja, arroz, coco, café, entre outras. Apesar da grande quantidade de informação sobre as espécies-praga, seu dano potencial nas plantas de importância econômica e as formas de controle usadas fazem com que o impacto dessas pragas na produção de colheitas permaneça em níveis indesejáveis. A caracterização ultra-estrutural da espermiogênese desses insetos poderá, possivelmente, ser importante para direcionar e programar um controle bioquímico e a manipulação genética por meio de machos estéreis ou semiestéreis. A espermiogênese normal envolve elongação nuclear, condensação cromatínica, formação do acrosoma e desenvolvimento flagelar, com a formação do axonema e dos derivados mitocondriais. O desenvolvimento do núcleo envolve mudanças na forma e no grau de condensação da cromatina que apresenta padrão fibrilar em alguns estágios de diferenciação. O acrosoma é formado pelo complexo de Golgi e pode apresentar características morfológicas pouco comuns aos outros Heteroptera durante seu desenvolvimento. O processo de espermiogênese também foi analisado durante a diapausa adulta de duas espécies de percevejos fitófagos. Os resultados indicam que, durante esse período, a espermiogênese é descontinuada e para isso conta com a participação de eventos com padrão apoptótico e fagocítico.
\end{abstract}

Palavras-chave: espermiogênese; insetos; ultra-estrutura.

\section{Comparative analysis of normal and diapausic spemiogenesis in phytophagous bugs (Hemiptera, Pentatomidae) - Revision}

\begin{abstract}
Phytophagous stink bugs (Hemiptera, Pentatomidae) are the main pests of economically important crops throughout the world, such as soybean, rice, cocoa and coffee among others. Despite the amount of information regarding pest species, their damage potential to economically important plants, and control measures
\end{abstract}

${ }^{1}$ Professora do Curso de Ciências Biológicas/Biomedicina da Faculdade de Ciências da Saúde-UniCEUB 


\section{Adrienne Fernandes}

used, the pests impact on the production of crops remains at undersirable levels. The ultrastructural characterization of these insects spermiogenesis would be important to programs directed towards the biochemical control of these insect pests and genetic manipulation through sterile and semisterile males. The normal spermiogenesis involves nuclear elongation, chromatin condensation, acrosomal formation and flagellar development along with formation of the axoneme as well as mitochondrial derivatives. The development of the nucleus involves changes in the shape and in degree of chromatin condensation which presents fibrillar pattern during some stages of differentiation. The acrosome is formed by the Golgi complex and can be present unusual morphological features with the other Heteroptera during its development. The spermiogenesis process was analised during adult diapause of two phytophagous bugs species. The results indicate that during this period the spermiogenesis is discontinued and for this, takes off cellular events with apoptotic and phagocytic pattern.

Key words: insects; spermiogenesis; ultra-structure.

A família Pentatomidae é uma das maiores famílias dentro dos Heteroptera, com mais de 4000 espécies descritas (Panizzi, 1997). A maioria dos pentatomídeos fitófagos é polífaga, alimentando-se em plantas cultivadas ou nativas. Eles são a maior peste de colheitas economicamente importantes ao redor do mundo, incluindo leguminosas como a soja (Turnipseed \& Kogan, 1976; Panizzi \& Slansky, 1985; Kogan \& Turnipseed, 1987); cereais como o arroz e o trigo (Oliver et al., 1971; Nilakhe, 1976; Jones \& Cherry, 1986; Foster et al., 1989) e colheitas de árvores como cítrus (James, 1992), coco (Dolling, 1984) e café (Greathead, 1966). Pentatomídeos fitófagos se alimentam em várias estruturas da planta hospedeira e, como conseqüência, a natureza da injúria que causam é variável, sendo que sementes e frutas imaturas são os principais sítios de alimentação.

O controle desses percevejos, assim como da grande maioria dos insetos vetores e pragas, tem sido feito com o uso indiscriminado de inseticidas, em detrimento ao equilíbrio biológico. Este método de controle, além de causar problemas ao homem e ao meio ambiente de um modo geral, pode eventualmente perder sua efetividade com a inevitável seleção de resistência pelo animal. Com estas preocupações, nestas últimas décadas, esforços foram concentrados com o intuito de desenvolver sofisticados métodos de controle, sendo que os mais usados são técnicas utilizando feromônios (Boake et al., 1996) e esterilidade, bem como outros métodos de controle genético (Rossler, 1982). Uma nova possibilidade de controle biológico pode ser estudada a partir da diapausa, que tem lugar durante a vida adulta de alguns desses percevejos fitófagos. 
Durante determinadas fases da vida de algumas espécies de insetos, pode ocorrer um retardo no desenvolvimento. Esse retardo é conhecido como quiescência - quando é uma conseqüência direta de condições ambientais - ou como diapausa - quando é um fenômeno adaptativo que habilita o inseto a sobreviver em condições adversas que ocorrem regularmente.

Em regiões temperadas, a diapausa está geralmente associada à sobrevivência do inseto no inverno gelado, quando a taxa de crescimento normal não é possível. Já nos trópicos, ela pode facilitar a sobrevivência durante a estação seca que é caracterizada pela baixa umidade e pela diminuição da oferta de alimento. Em insetos que sofrem uma diapausa obrigatória em cada geração, o estágio particular de entrada na diapausa é determinado geneticamente. Mas quando a diapausa ocorre somente em certas gerações, as mudanças no metabolismo são iniciadas por algum sinal vindo do ambiente que, embora não desfavorável por ele mesmo, indica o advento de uma condição adversa (Chapman, 1998). Assim sendo, os insetos são capazes de sobreviver na ausência de alimento e sob condições climáticas adversas pela entrada em períodos de dormência e inatividade reprodutiva.

Durante a diapausa larval e pupal, a espermiogênese sofre profundas alterações devido ao novo balanço endócrino estabelecido. Essas alterações na espermiogênese são causadas pela lise das células germinativas em desenvolvimento que tenham alcançado um certo grau de maturação e este é característico para uma dada espécie (Chippendale \& Alexander, 1973). No final da diapausa, o balanço endócrino é restabelecido e as células germinativas param de ser lisadas, fazendo com que a espermatogênese prossiga ininterruptamente como antes da diapausa (Herman, 1981; Friedländer, 1982; 1997; Friedländer \& Reynolds, 1992).

A maioria dos trabalhos sobre gametogênese, durante a diapausa adulta, tem sido feita durante a oogênese (Denlinger, 1985). Os dados publicados sobre a diapausa adulta de machos referem-se, principalmente, ao comportamento sexual, às glândulas acessórias e à competição de espermatozóides (Ferenz, 1975; Glitho \& Huignard, 1990; Pener, 1992). Assim, pouco se conhece sobre a espermatogênese durante esse período (de Wilde, 1954; Tran \& Huignard, 1992; Friedländer \& Scholtz, 1993). Também não há informações sobre as mudanças estruturais e ultra-estruturais ocorridas na espermiogênese de insetos adultos, no período da diapausa.

Os espermatozóides típicos de insetos apresentam forma alongada e diâmetro reduzido, escasso citoplasma e duas regiões distintas: a cabeça e a cauda, geralmente conectadas pelo adjunto do centríolo (Philips, 1970; Baccetti, 1972). A cabeça é constituída pelo acrosoma e o núcleo. A cauda é formada pelo axonema, derivados mitocondriais e estruturas acessórias. $\mathrm{O}$ acrosoma é formado a partir 
do complexo de Golgi e seu conteúdo é rico em enzimas hidrolíticas (Baccetti, 1972; Báo et al., 1989; Báo \& de Souza, 1992). O axonema, na grande maioria dos insetos, apresenta o padrão de 9+9+2 microtúbulos, sendo 2 microtúbulos centrais, 9 duplas periféricas e 9 microtúbulos acessórios (Phillips, 1970; Baccetti, 1972). Geralmente apresentam dois derivados mitocondriais flanqueando o axonema, que podem ser do mesmo tamanho e conter matriz paracristalina (Phillips, 1970; Baccetti, 1972; Baccetti et al., 1977).

Além das características comuns aos espermatozóides dos demais insetos, os de Heteroptera apresentam algumas que são exclusivas à Ordem, não sendo encontradas nos espermatozóides de outros insetos: dois ou três corpúsculos paracristalinos nos derivados mitocondriais e pontes entre os derivados mitocondriais e dois dos microtúbulos axonemais (Afzelius et al., 1976; 1985; Dallai \& Afzelius, 1980; Dolder, 1988; Afzelius \& Dallai, 1989; Báo \& de Souza, 1994; Fernandes \& Báo, 1998).

A espermiogênese normal desse grupo de insetos-praga foi descrita detalhadamente por Fernandes \& Báo $(1998$; 2001a) e por Fernandes \& colaboradores (2001a). No entanto, algumas características merecem detalhamento especial, como a formação do acrosoma e o desenvolvimento/maturação do núcleo que parecem ser bastante específicos (Fernandes \& Báo, 2001a; Fernandes et al., 2001a). A formação do acrosoma conta com a participação de várias enzimas como fosfatase ácida, glicose-6-fosfatase e tiaminopirofosfatase, além da presença de resíduos de carboidratos. Durante os estágios finais, essa estrutura mostra um arranjo tubular que permanece no acrosoma maduro, que por sua vez é constituído de três partes distintas: um cone interno eletron lucente, o conteúdo acrosomal (com arranjo tubular) e a membrana extra-acrosomal. Durante a maturação do núcleo, a cromatina passa de granulada ou descompactada à totalmente compactada, apresentando um arranjo fibrilar, nos estágios intermediários. A elucidação das atividades enzimáticas e a localização de resíduos de carboidratos ajudam a esclarecer alguns aspectos particulares da espermiogênese desses insetos. Esses resultados (Fernandes et al., 2001a) mostram que espécies diferentes usam diferentes resíduos de carboidratos e enzimas para controlar seu próprio desenvolvimento, indicando que a presença e o significado funcional dos carboidratos e das enzimas durante o processo espermiogênico parece ser espécie-específico.

Outro aspecto importante é a detecção/localização de cálcio e calmodulina durante a espermiogênese dos pentatomídeos (Fernandes \& Báo, 2001b). Embora tenha sido descrita a participação desses elementos na formação do acrosoma (Kann et al., 1991), na capacitação (Leclerc et al., 1990) e na reação de fusão do ovo com o espermatozóide (Aitken et al., 1988) em espécies animais diferentes, nos Heteroptera analisados esses eventos parecem ser feitos ou controlados por 
outros mecanismos sem a participação de cálcio e calmodulina (Fernandes \& Báo, 2001b). Entretanto, conforme sugerido por Gibbons (1982) e Tash (1989), esses elementos podem estar envolvidos no controle do batimento flagelar e em outros eventos celulares não relacionados com essa função.

As tubulinas são as principais proteínas encontradas nos espermatozóides de animais. A caracterização dos microtúbulos das células espermáticas e a localização, por meio de imunocitoquímica, de tubulinas modificadas póstraducionalmente mostrou que existem diferenças significativas entre os microtúbulos axonemais e citoplasmáticos (Fernandes \& Báo, 2002). O significado funcional dessas diferenças ainda não foi elucidado. Entretanto, parece que sua composição pode determinar propriedades químicas e físicas dos microtúbulos - componentes do citoesqueleto importantes para o desenvolvimento dos espermatozóides.

Além das transformações ocorridas durante a espermiogênese desses insetos, os espermatozóides maduros já ejaculados sofrem uma série de transformações citoquímicas, durante o período que permanecem na espermateca das fêmeas (Fernandes \& Báo, 2000). Essas transformações parecem estar relacionadas com a preparação do espermatozóide para a fertilização ou com a sobrevivência dessas células por longos períodos dentro da espermateca. Todavia, são necessários maiores estudos para esclarecer o verdadeiro papel das enzimas nos espermatozóides durante esse período de sobrevivência na fêmea.

A diapausa é uma fase da vida controlada geneticamente onde ocorrem ajustes bioquímicos e comportamentais que garantem a sobrevivência dos insetos em períodos com pouco ou nenhuma oferta de alimento e baixa umidade. A espermiogênese de Edessa meditabunda e Nezara viridula durante a diapausa adulta apresenta algumas características interessantes, como por exemplo a presença de inúmeros corpúsculos residuais que sugerem a eliminação de células germinativas durante seu desenvolvimento e a interrupção da espermiogênese normal (Fernandes et al., 2001b).

\section{Conclusão}

Com base nas características descritas durante essa breve revisão pudemos concluir que:

- A espermiogênese desses percevejos fitófagos é complexa e envolve a elongação nuclear, formação do acrosoma, desenvolvimento flagelar com surgimento do axonema e dos derivados mitocondriais.

- Os espermatozóides desses percevejos apresentam as mesmas caracterís- 
ticas ultra-estruturais descritas anteriormente para outros Heteroptera: núcleo, acrosoma, axonema com o padrão de 9+9+2 microtúbulos, dois derivados mitocondriais contendo duas estruturas paracristalinas cada um e pontes conectando os microtúbulos axonemais 1 e 5 e os derivados mitocondriais.

- As mudanças nucleares e a formação do acrosoma contam com a participação de diferentes enzimas e resíduos de carboidratos.

- Várias isoformas de tubulinas são imunocitoquimicamente detectadas durante a espermiogênese desses percevejos.

- Durante a espermiogênese, pode ser detectada a participação de cálcio e calmodulina que, além de estarem envolvidos no controle do batimento flagelar, participam de outros eventos regulatórios no desenvolvimento das espermátides.

- Embora não haja mudanças morfológicas nos espermatozóides desses insetos após a cópula, não há dúvidas que ocorrem várias mudanças fisiológicas nessas células antes da fertilização.

- Durante a diapausa adulta sofrida por algumas espécies de percevejos fitófagos, a espermiogênese é descontinuada com a participação de eventos celulares com padrão apoptótico e fagocítico.

\section{Referências bibliográficas}

AFZELIUS, B. A; DALLAI, R. Connecting bridges between axoneme and othe components in the sperm tail of some insects. J. Morphol., v. 202, p. 173-177, 1989.

AFZELIUS, B. A.; BACCETTI, B.; DALLAI, R. The giant spermatozoon of Notonecta. J. Submicrosc. Cytol., v. 8, p. 149-161, 1976.

AFZELIUS, B. A.; DALLAI, R.; LINDSKOG, P. Spermatozoa of saldid bugs (Insecta, Hemiptera, Leptopodomorpha). J. Ultrastruct. Res., v. 90, p. 304-312, 1985.

AITKEN, R. J.; CLARKSON, J. S.; HULME, M. J.; HENDERSON, C. J. Analysis of calmodulin acceptor proteins and the influence of calmodulin antagonists on human spermatozoa. Gamete Res., v. 21, p. 93-111, 1988.

BACCETTI, B. Insect sperm cells. Adv. Insect Physiol., v. 9, p. 315-397,1972.

BACCETTI, B.; DALLAI, R.; PALLINI, V.; ROSATI, F.; AFZELIUS, B. A. Protein of insect sperm mitochondrial crystals: crystallomitin. J. Cell Biol., v. 73, p. 594-600, 1977.

BÁO, S. N.; DE SOUZA, W. Lectin binding sites on head structures of the spematid and spermatozoon of the mosquito Culex quinquefasciatus (Diptera, Culicidae). Histochemistry, v. 98, p. 365-371, 1992.

BÁO, S. N.; DE SOUZA, W. Structural specialization in the flagellum of the spermatozoon of the bloodsucking bug (Rhodinius prolixus; Hemiptera, Reduviidae). Tissue Cell, v. 
26, p. 299-308, 1994.

BÁO, S. N.; DOLDER, H. QUAGIO-GRASSIOTTO, I. Acrosome formation in Ceratitis capitatai (Diptera, Tephritidae). CytobiosJ, v. 58, p. 93-100, 1989.

BOAKE, C. R. B.; SHYELL, T. E.; KANESHIRO, K. Y. Sexual selection in relation to pestmanagement strategies. Ann. Rev. Entomol.J, v. 41, p. 211-231, 1996.

CHAPMAN, R. F. The insects structure and function. 4. ed. Cambridge: Cambridge Univ. Press, 1998. 770 p.

CHIPPENDALE, G. M.; ALEXANDER, B. R. Spermatogenesis in the south-wester corn borer, Oiabrotica grandiosella 2. Resumption in diapause larvae. Ann. Entomol. Soc. Am., v. 66, p. $747-752,1973$.

DALLAI, R. AFZELIUS, B. A. Characteristic of the sperm structure in Heteroptera (Hemiptera, Insecta). J. Morphol., v. 164, p. 301-309, 1980.

DENLINGER, D. L. Hormonal control of diapause. In: G.A. KERKUT; L. I. GILBERTI: Comprehensive insect physiology, Biochemisty and Pharmacology. Oxford: Pergamon Press, p. 353-412,1985.

DOLDER, H. Cytoskeletal bridges between organelles in sperm flagellum of Triatoma infestans (Hemiptera, Reduviidae). J. Ultrastruct. MoI. Struct. Res., v. 101, p. 159-164,1988.

DOLLING, W. R. Pentatomid bugs (Hemiptera) that transmit a flagellate disease of cultivated palms in South America. Bul Entomol. Res. v. 47, p. 473-74,1984.

FERENZ, H. J. Photoperiod and hormonal control of reproduction in male beetles, Pterostichus nigrita. J lnsect Physiol., v. 21, p. 331-341,1975.

FERNANDES, A. P .; BÁO, S. N. Spermiogenesis in phytophagous bug (Hemiptera, Pentatomidae): an ultrastructural study. J. Submicrosc. Cytol Pathol., v. 30, n. 4, p. 485-493, 1998.

FERNANDES, A. P.; BÁO, S. N. Ultrastructural and cytochemical studies of the spermatozoa of Acrasternum aseadum (Hemiptera: Pentatomidae) after copulation. J. Submicrosc. Cytol. Pathol, v. 32, n. 4, p. $547-553,2000$.

FERNANDES, A. P.; BAO, S. N. Ultrastructural studies on spermiogenesis and spermatozoa of insect pests (Hemiptera: Pentatomidae). In: Sarma, R. Current Res. Adv. in Agricul. \& Entamal. Kerala-lndia, World Wide Research, p. 13-26, 2001a.

FERNANDES, A. P; BÁO, S. N. Detection of calcium and calmodulin during spermiogenesis of phytophagous bugs (Hemiptera: Pentatomidae). BiaCell, v. 25, . n.2, p. 173-177, $2001 b$.

FERNANDES, A. P.; BÁO, S. N. Immunoelectron microscopy detection of tubulins during the spermiogenesis of phytophagous bugs (Hemiptera: Pentatomidae). Invertebrate Repraductian \& Develapment (in press), 2002.

FERNANDES, A. P.; CURI, G.; FRANCA, F. G. R.; BAO, S. N. Nuclear changes and acrosome formation during spermiogenesis in Euchistus heros (Hemiptera: Pentatomidae). Tissue \& Cell, v. 33, n.3, p. 286-293, 2001a.

FERNANDES, A. P.; PEIXOTO, F. L.; BAO, S. N. Ultrastructural and cytochemical studies 
on diapause spermiogenesis in phytaphagous bugs (Hemiptera:Pentatomidae). Submetido à publicação, 2001b.

FOSTER, R. E.; CHENY, R. H.; JONES, D. B. Spatial distribution of the rice stink bug (Heteroptera: Pentatomidae) in Florida rice. J. Econ. Entomol., v. 82, p. 507- 509,1989.

FRIEDLANDER, M. Juvenile hormone and regulation of dichotomous spermatogenesis during the larval diapause of codlin moth. J. Insect Physiol., v. 28, p. 1009-1012,1982.

FRIEDLANDER, M. Control of the eupyrene-apyrene sperm dimorphism in Lepidoptera. J. Insect Physiol., v. 43, p. 1085-1092, 1997.

FRIEDLANDER, M.; REYNOLDS, S. E. Itratesticular ecdisteroid titers and the arrest of sperm production during pupal diapause in the tobacco hornworm Manduca sexta. J. Insect Physiol., v. 38, p. 693-703, 1992.

FRIEDLANDER, M.; SCHOLTZ, C. H. Two different pattern of interrupted spermatogenesis in winter diapause and summer quiescence in the desert beetle, Omorgus freyi. J. Morphol., v. 218, p. 372-378, 1993.

GIBBONS, I. R. Sliding and bending in sea urchin sperm flagella. Symp. Soc. Exp. Biol., v. 35 , p. 225-287, 1982.

GLITHO, I. A.; HUIGNARD, J. A histological and ultrastructural comparison of the male accessory reproductive glands of diapausing and non-diapausing adults in Brochidius atrolineatus (Pic). (Coleoptera, Bruchidae). Int. J. Insect Morphol. Embryol., v. 19, p. 195-209, 1990.

GREATHEAD, D. J. A taxonomic study of the species of Antestiopsis (Hemiptera: Pentatomidae) associated with Coffea arabica in Africa. BulI. Entomol. Res., v. 56, p. 515-554,1966.

HERMAN, W. S. Studies on the adult reproductive diapause of the monarch butterfly Danusplexippus. Biol. Bull., v. 160, p. 89-106,1981.

JAMES, D. G. Effect of citrus host variety on oviposition, fecundity and longevity in Biprorulus bibax (Breddin)(Heteroptera). Acta Entomol. Bohemoslov, v. 89, p. 65- 67, 1992.

JONES, D. B.; CHERRY, R. H. Species composition and seasonal abundance of stink bugs (Heteroptera: Pentatomidae) in southern Florida rice. J. Econ. Entomol., v. 79, p. 1226-1229, 1986.

KANN, M. L.; FEINBERG, J.; RAINTEAU, D.; DADOUNE, J. P.; WEINMAN, S.; FOUQUET, J. P. Localization of calmodulin in perinuclear structures of spermatids and spermatozoa: a comparison of six mammalian species. Anat. Rec., v. 230, p. 481-488, 1987.

KOGAN, M.; TURNIPSEED, S. G. Ecology and management of soybean arthropods. Ann. Rev. Entomol., v. 32, p. 507-538,1987.

LECLERC, P.; SIRARD, M. .A.; CHAFOULES, J. G.; LAMBERT, R. D. Decreased binding of calmodulin to bull sperm proteins during heparin-induced capacitation. Biol. Reprod., v. 42, p. 483-489, 1990.

NILAKHE, S. S. Overwintering, survival, fecundity and mating behaviour of the rice stink 
bug. Ann. Entomol. Soc. Am., v. 69, p. 717-720, 1976.

OLIVER, B. F.; GIFFORD, J. R.; TRAHAN, G. B. Ultra-low-volume insecticides to control the rice stink bug in southwest Louisiana. J. Econ. Entomol., v. 54, p. 981- 983, 1971.

PANIZZI, A R. Wild hosts of Pentatomids: ecological significance and role in their pest status on crops. Ann Ver. Entomol., v. 42, p. 99-122, 1997.

PANIZZI, A. R.; SLANSKY, F. Review of phytophagous pentatomids (Hemiptera: I Pentatomidae) associated with soybean in the Americas. Fia. Entomol., v. 68, p. 184214, 1985.

PENER, M. P. Enviromental cues, endocrine factors, and reproductive diapause in male insects. Chronobiol. Int., v. 9, p. 102-113, 1992.

PHILLIPS, D. M. Insect sperm: their structure and morphogenesis. J. Cell Biol., v. 44, p. 243-277, 1970.

ROSSLER, Y. Recombination in males e females of the mediterranean fruit fly (Diptera, Tephritidea) with or without chromosomal aberration. Ann. Entomol. Soc. Am., v. 75, p. 619-622, 1982.

TASH, J. D. Protein phosphorylation: the second messenger signal transducer of flagellar motility. Cell Mot Cytoskeleton, v. 14, p. 332-339, 1989.

TRAN, B.; HUIGNARD, J. Interactions between photoperiod and food affect the termination of reproductive diapause in Bruchus rufimanus (Boh)(Coleoptera, Bruchidae). J. Insect Physiol., v. 38, p. 633-642, 1992.

TURNIPSEED, S. G.; KOGAN, M. Soybean entomology. Ann. Rev. Entomol., v. 21, p. 247 $-282,1976$.

WILDE, J. Aspects of diapause in adult insects with special regard to the Colorado beetle, Leptinotarsa decemlineata. Arch. Neerl. Zool., v. 10, p. 375-385, 1954. 